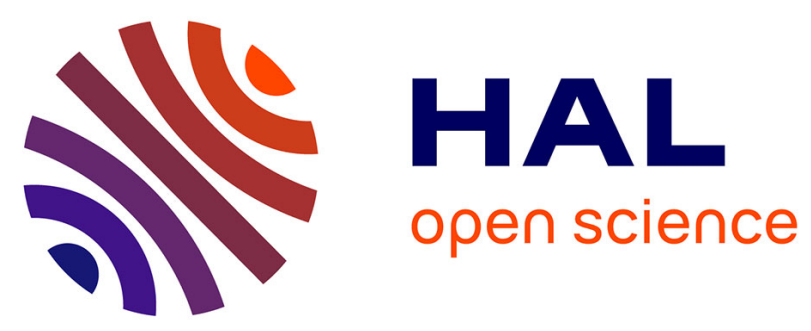

\title{
Photo-Cross-Linked Self-Assembled Poly(ethylene oxide)-Based Hydrogels Containing Hybrid Junctions with Dynamic and Permanent Cross-Links
}

Erwan Nicol, Taco Nicolaï, Jingwen Zhao, Tetsuharu Narita

\section{- To cite this version:}

Erwan Nicol, Taco Nicolaï, Jingwen Zhao, Tetsuharu Narita. Photo-Cross-Linked Self-Assembled Poly(ethylene oxide)-Based Hydrogels Containing Hybrid Junctions with Dynamic and Permanent Cross-Links. ACS Macro Letters, 2018, 7 (6), pp.683-687. 10.1021/acsmacrolett.8b00317 . hal01945126

\author{
HAL Id: hal-01945126 \\ https: / hal.sorbonne-universite.fr/hal-01945126
}

Submitted on 5 Dec 2018

HAL is a multi-disciplinary open access archive for the deposit and dissemination of scientific research documents, whether they are published or not. The documents may come from teaching and research institutions in France or abroad, or from public or private research centers.
L'archive ouverte pluridisciplinaire HAL, est destinée au dépôt et à la diffusion de documents scientifiques de niveau recherche, publiés ou non, émanant des établissements d'enseignement et de recherche français ou étrangers, des laboratoires publics ou privés. 


\title{
Photo-Cross-Linked Self-Assembled Poly(Ethylene Oxide) Based Hy- drogels Containing Hybrid Junctions with Dynamic and Permanent Crosslinks
}

\author{
Erwan Nicol ${ }^{\mathrm{a}, *}$, Taco Nicolai ${ }^{\mathrm{a}}$, Jingwen Zhao ${ }^{\mathrm{b}}$, Tetsuharu Narita ${ }^{\mathrm{b}, \mathrm{c}}$ \\ ${ }^{\text {a }}$ IMMM - UMR CNRS 6283, Le Mans Université, avenue O. Messiaen, 72085 Le Mans cedex 9, France \\ b Laboratoire Sciences et Ingénierie de la Matière Molle, ESPCI Paris, PSL University, Sorbonne Université, CNRS, 75005 \\ Paris, France \\ ${ }^{c}$ Global Station for Soft Matter, Global Institution for Collaborative Research and Education, Hokkaido University, Sapporo, \\ Japan \\ Supporting Information Placeholder
}

\begin{abstract}
Homogeneous hydrogels were formed by selfassembly of triblock copolymers via association of small hydrophobic endblocks into micelles bridged by large poly(ethylene oxide) central blocks. A fraction of the endblocks was photocross-linkable and could be rapidly crosslinked covalently by insitu UV irradiation. In this manner networks were formed with well defined chain lengths between homogeneously distributed hybrid micelles that contained both permanent and dynamically crosslinked endblocks. Linear rheology showed a single relaxation mode before in-situ irradiation intermediate between those of the individual networks. The presence of transient crosslinks decreased the percolation threshold of the network rendered permanent by irradiation and caused a strong increase of the elastic modulus at lower polymer concentrations. Large amplitude oscillation and tensile tests showed significant increase of the fracture strain caused by the dynamic crosslinks.
\end{abstract}

Hydrogels are soft materials containing a large volume fraction of water. Due to their physical properties close to those of tissues in humans, they are of great interest in the biomedical field for drug or protein delivery ${ }^{1-10}$, tissue engineering ${ }^{2,7,8,11-20}$ or cell immobilization $^{1,8,21}$. However, hydrogels usually suffer from poor mechanical properties that limit their use in applications. This is true in particular for poly(ethylene oxide) (PEO), which is one of the most commonly used synthetic polymers for biomedical applications ${ }^{22}$. Various strategies have been developed to address this problem ${ }^{23}$ such as topological gels ${ }^{24}$, interpenetrated polymer networks $(\mathrm{IPN})^{25}$, 26, double networks (DN $)^{27-29}$, nanocomposite gels ${ }^{30}, 31$ or flawless networks ${ }^{32}, 33$ with impressive improvement of toughness. However, most of these hydrogels are synthesized by free radical polymerization (FRP) or "click coupling" which limits their application if injectability or biocompatibility is needed. It also involves out of equilibrium formation of the gels leading to ill-defined networks. Polymeric hydrogels can be formed in dynamic equilibrium by exploiting the spontaneous association of triblock copolymers containing hydrophobic endblocks and a hydrophilic central block ${ }^{34-36}$. Transient crosslinks can subsequently be rendered covalent by introducing photocrosslinkable units within the hydrophobic blocks ${ }^{37-39}$.

This approach has been exploited in the past to form interpenetrated self-assembled polymer networks (IPSAN) by mixing two types of triblock copolymers that formed independent interpenetrated networks ${ }^{40}$. The transient crosslinks of one network were subsequently rendered covalent by in-situ UV irradiation. Even though the networks were topologically independent, physical interaction between both networks led to a shift of the percolation concentration $\left(C_{\mathrm{p}}\right)$ and to a large increase of the elastic modulus compared to simple additivity. However, no significant enhancement of the gel toughness was observed, which we attribute to the fact that the networks were independent.

Here, self-assembly of triblock copolymers is exploited in a different manner. Two types of copolymers are mixed with the same central PEO block and different relatively short hydrophobic endblocks. Crosslinks formed by one type of endblock can be rendered covalent by in-situ UV irradiation, whereas the other remains dynamic. It will be shown that the two types of endblocks are randomly mixed in hybrid micellar cores. In this manner we were able to synthesize for the first time homogeneous selfassembled hydrogels containing both dynamic and permanent crosslinks with well-defined chain lengths between the crosslinks.

The dynamic network was formed by association of poly(isobutyryloxyethyl acrylate)- $b$-poly(ethylene oxide)- $b$ poly(isobutyryloxyethyl acrylate) (PIEA $7-b-\mathrm{PEO}_{270}-b-\mathrm{PIEA}_{7}$ called $\left.\mathrm{IEI}_{12 \mathrm{~K}}\right)$. The photo-cross-linkable network was formed by poly(methacryloyloxyethyl acrylate)- $b$-poly(ethylene oxide)- $b$ poly(methacryloyloxyethyl acrylate) (PMEA $7-b-\mathrm{PEO}_{270}-b-$ $\mathrm{PMEA}_{7}$ and $\mathrm{PMEA}_{9}-b-\mathrm{PEO}_{800}-b-\mathrm{PMEA}_{7}$ called $\mathrm{tPEO}_{12 \mathrm{~K}}$ and $\mathrm{tPEO}_{35 \mathrm{k}}$, respectively) These copolymers were synthesized following methods published elsewhere ${ }^{40-43}$ (see Supporting Information) according to the route shown in Scheme 1. In aqueous solution $\mathrm{IEI}_{12 \mathrm{~K}}$ and $\mathrm{tPEO}$ self-assemble into flower-like micelles that can bridge leading to a network above $C_{\mathrm{p}}$. The apparent molar masses $\left(M_{\mathrm{a}}\right)$ and hydrodynamic radii $\left(R_{\mathrm{a}}\right)$ of the micelles obtained from light scattering were close to the averages calculated from values obtained with individual systems (see Supporting Information). It follows that either the aggregation number ( $\left.N_{\text {agg }}\right)$ of the hybrid micelles was the same as the calculated average or that hybridization had not occurred.

Scheme 1. Synthesis of PMEA-b-PEO-b-PMEA (tPEO) and PIEA-b-PEO-b-PIEA (IEI) triblock copolymers. 


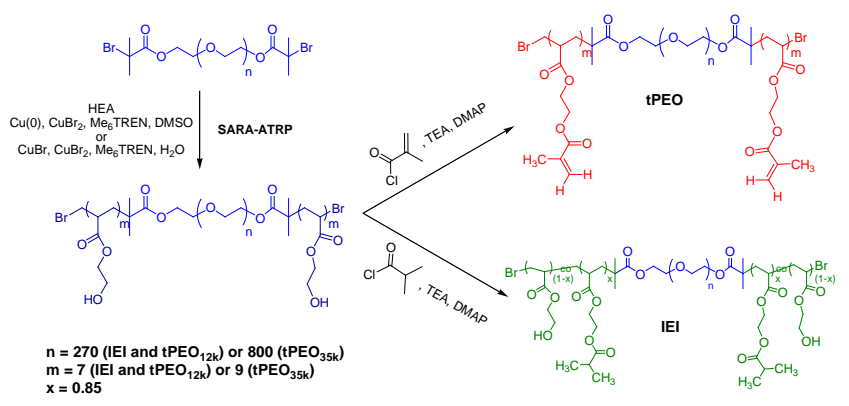

Formation of transient networks by the copolymers caused a sharp increase of the relative viscosity $\left(\eta_{\mathrm{r}}\right)$ with increasing concentration above $C_{\mathrm{p}}: C_{\mathrm{p}} \approx 15 \mathrm{~g} / \mathrm{L}$ for $\mathrm{tPEO}_{12 \mathrm{k}}$ and $\mathrm{IEI}_{12 \mathrm{~K}}$ and $C_{\mathrm{p}} \approx 8 \mathrm{~g} / \mathrm{L}$ for $\mathrm{tPEO}_{35 \mathrm{k}}$ (Figure S5). The mechanical relaxation of transient gels formed by self-assembly of tPEO/IEI mixtures above $C_{\mathrm{p}}$ was determined by oscillatory shear measurements. The frequency dependence of the storage $\left(G^{\prime}\right)$ and loss $\left(G^{\prime \prime}\right)$ shear moduli showed a single relaxation mode that shifted to lower frequencies with increasing weight fraction of tPEO $(x)$ in the mixtures (Figure S6). Master curves could be obtained by superimposition of results obtained at different concentrations, different chain lengths and different weight fraction using horizontal $\left(a_{\mathrm{x}}\right)$ and vertical $\left(b_{\mathrm{x}}\right)$ shift factors, see Figure 1a. This implies that the relaxation process of all systems was similar with a characteristic relaxation time that depended on the composition.

The relaxation time $(\tau)$ was defined here as the inverse of the radial frequency $(1 / 2 \pi v)$ at which $G^{\prime}$ crossed G". It was intermediate between that of the individual gels and increased exponentially with $x$, see Figure $1 \mathrm{~b}$. These observations are best explained if we assume that the network was formed by bridged hybridized micelles so that the escape of PMEA was facilitated by the presence of PIEA and the escape of PIEA was slowed down by the presence of PMEA leading to single intermediate relaxation time.

The self-assembled transient hybrid gels were subsequently irradiated with UV-light in the presence of a photoinitiator, which caused covalent cross-linking of the PMEA endblocks of tPEO within the micellar cores. In-situ measurements during photocross-linking showed a very rapid increase of $G^{\prime}$ upon irradiation, see Figure 2a and Figure S7. The appearance of a frequency independent storage modulus higher than $G^{\prime \prime}$ at low frequencies confirmed the formation of a covalent hydrogel, see Figure $2 b$ and Figure S8. Mixtures with relatively high concentrations of IEI $_{12 \mathrm{~K}}$ still showed significant relaxation of $G^{\prime}$ at high frequencies. We suggest that this was caused by escape of PIEA blocks implying that permanently cross-linking PMEA by UV-irradiation did not trap the PIEA blocks that were present in the same hybrid cores (scheme 2).
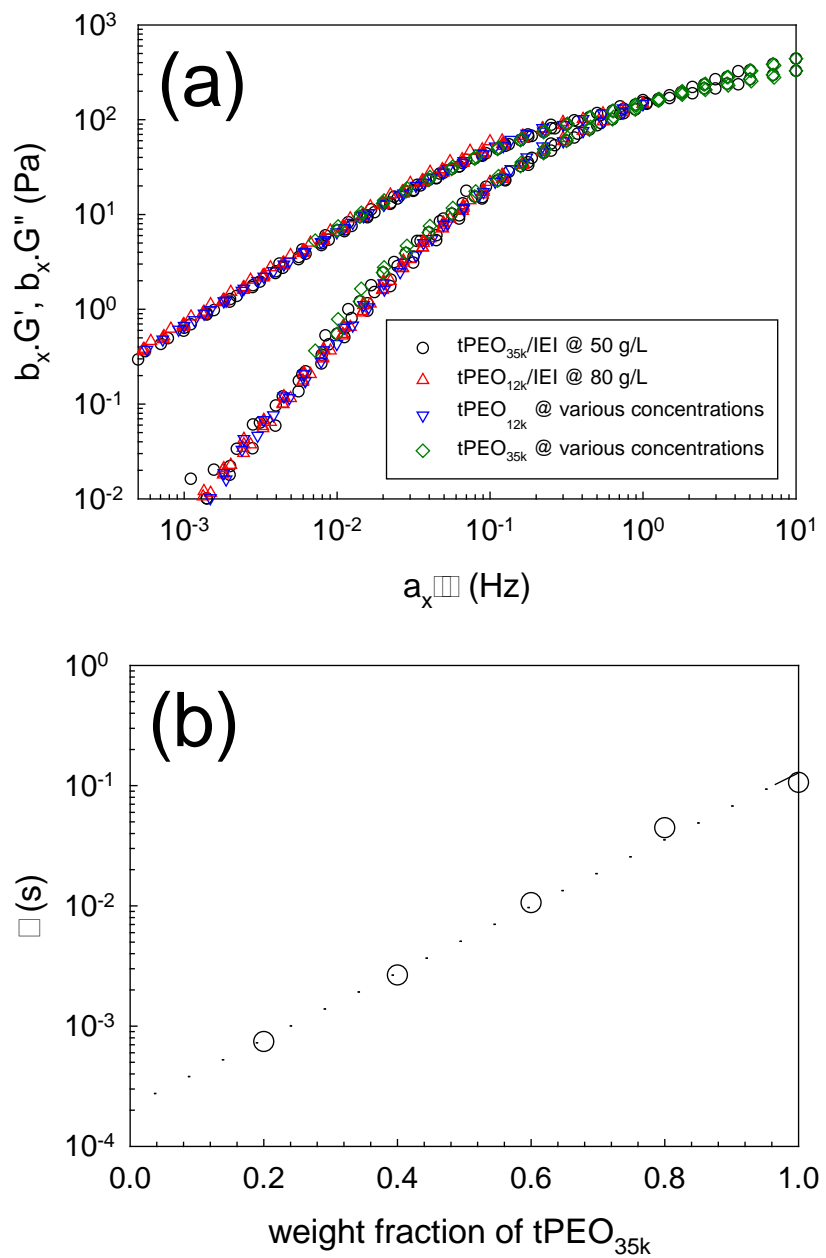

Figure 1. (a) Master curve obtained by superimposition the relaxation spectra of pure tPEO solutions and tPEO/IEI ${ }_{12 \mathrm{~K}}$ mixtures (reference curve: $\mathrm{tPEO}_{35 \mathrm{k}}$ at $C=50 \mathrm{~g} / \mathrm{L}$ and $T=20^{\circ} \mathrm{C}$ ). (b) Evolution of the relaxation time with the weight fraction of $\mathrm{tPEO}_{35 \mathrm{k}}$ in $\mathrm{tPEO}_{35 \mathrm{k}} / \mathrm{IEI}_{12 \mathrm{~K}}$ mixtures at $C_{\text {tot }}=50 \mathrm{~g} / \mathrm{L}$ and $T=20^{\circ} \mathrm{C}$.

Scheme 2. Schematic representation of hybrid dynamic/covalent self-assembled photo-cross-linked hydrogels.

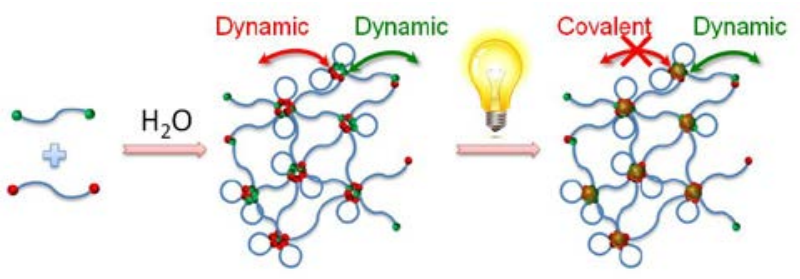

Flowing hydrogel 

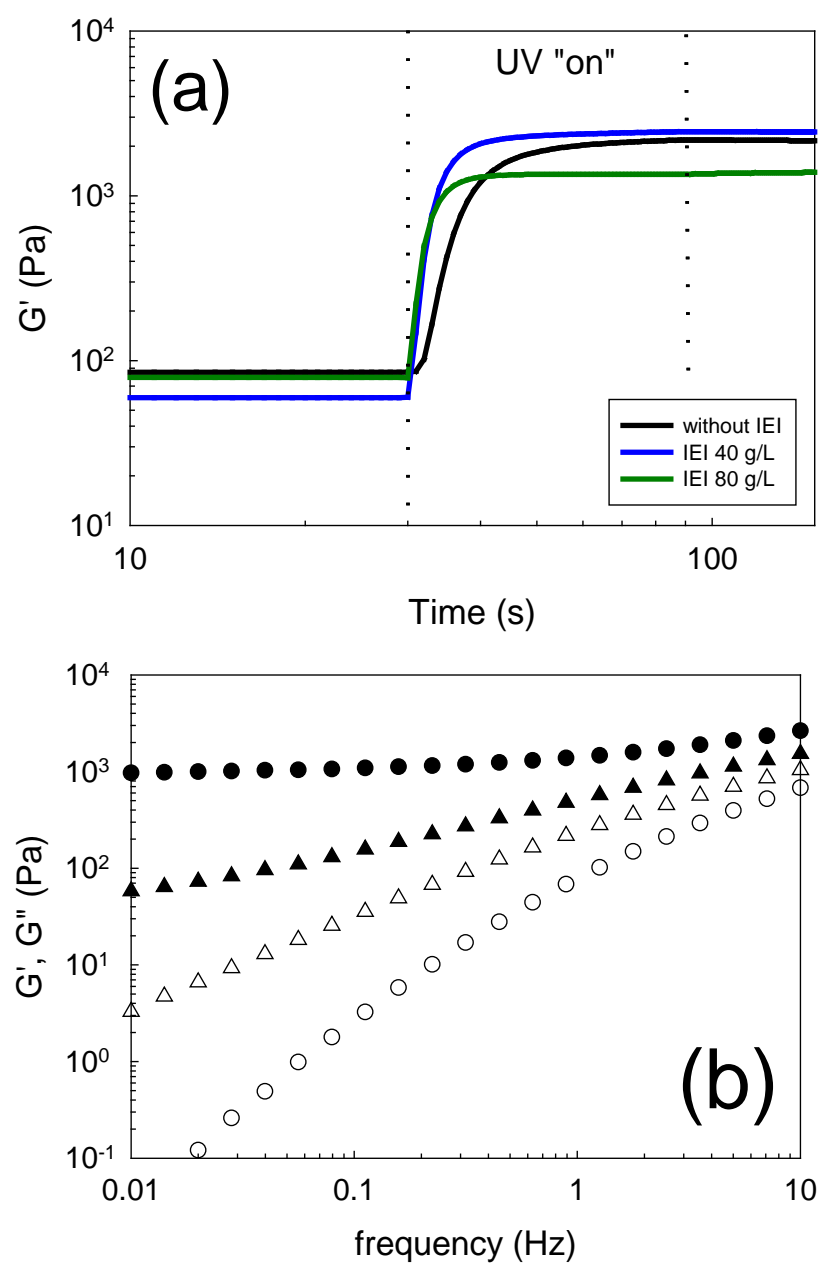

Figure 2. (a) Evolution of the elastic modulus $\left(G^{\prime}\right)$ during the photo-cross-linking step of $\mathrm{tPEO}_{35 \mathrm{k}} / \mathrm{IEI}_{12 \mathrm{~K}}$ hybrid hydrogels at constant $\mathrm{tPEO}_{35 \mathrm{~K}}$ concentration $C_{\mathrm{tPEO}}=40 \mathrm{~g} / \mathrm{L}$ and various $\mathrm{IEI}_{12 \mathrm{~K}}$ concentration indicated in the Figure. $(\gamma=2 \%, f=1 \mathrm{~Hz})$. (b) Frequency dependence of the storage $\left(G^{\prime}\right.$, circles) and loss $\left(G^{\prime \prime}\right.$, triangles) moduli before (open symbols) and after UV-irradiation (filled symbols) of $\mathrm{tPEO}_{35 \mathrm{k}} / \mathrm{IEI}_{12 \mathrm{~K}}(40 \mathrm{~g} / \mathrm{L}-80 \mathrm{~g} / \mathrm{L})$ mixture.

At low frequencies the dynamic IEI $_{12 \mathrm{~K}}$ network has completely relaxed and $G^{\prime}$ at $0.01 \mathrm{~Hz}$ is equal to the elastic modulus $\left(G_{0}\right)$ of the covalent network. Assuming rubber elasticity and affine deformation, the ideal elastic modulus is obtained if all tPEO chains are elastically active: $G_{0}=C R T / M_{\mathrm{n}}$. The calculated moduli are $0.58,1.15$ and $2.31 \mathrm{kPa}$ for $\mathrm{tPEO}_{35 \mathrm{k}}$ hydrogels, at $C=10,20$ and $40 \mathrm{~g} / \mathrm{L}$, respectively. As shown in Figure 3, close to $C_{\mathrm{p}}$ individual tPEO hydrogels formed imperfect networks in which the fraction of elastically active chains is small. Increasing the concentration increased the fraction of elastically active chains leading to a fully formed network at $C>40 \mathrm{~g} / \mathrm{L}$ for $\mathrm{tPEO}_{35 \mathrm{k} \text {. }}$

For tPEO concentrations above, but close to $C_{p}$, addition of IEI $_{12 \mathrm{~K}}$ triblock copolymer led to an increase of $G_{0}$, see Figure 3 and Figure S9. Considering that at low frequencies $\mathrm{IEI}_{12 \mathrm{~K}}$ chains no longer contributed to the shear modulus, the increase of $G_{0}$ was caused by an increasing number of elastically active tPEO chains in the network. In the case of highly imperfect tPEO networks close $C_{\mathrm{p}}$, the increase caused by adding IEI $\mathrm{I}_{12 \mathrm{~K}}$ could be as much as two orders of magnitude (Figure S9). This means that adding $\mathrm{IEI}_{12 \mathrm{~K}}$ improves the connectivity of the tPEO network, though $G_{0}$ did not reach the values calculated for ideal tPEO networks.

Interestingly, similar improvement of the mechanical properties could be obtained by addition of the diblock copolymer poly(isobutyryloxyethyl acrylate)- $b$-poly(ethylene oxide) $5 \mathrm{k}$ (IE).

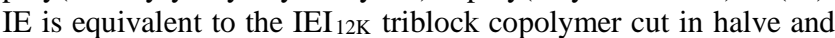
cannot bridge micelles (Figure S10). This means that the effect of $\mathrm{IEI}_{12 \mathrm{~K}}$ on the elastic modulus of the tPEO network is not caused by transient bridging of IEI $12 \mathrm{~K}$, but by the presence of dynamic hydrophobic blocks in the hybrid micellar cores.

As was mentioned above, light scattering measurements showed that $N_{\text {agg }}$ of the hybrid micelles was close to the average of the individual systems. The implication is that added PIEA blocks of either IE or IEI $12 \mathrm{~K}$ substituted PMEA blocks of tPEO in the micellar cores. This caused an increase of the concentration of micelles containing $\mathrm{TPEO}$, which in turn favored the formation of bridges instead of loops by $\mathrm{TPEO}$ and therefore an increase of the fraction of elastically active tPEO chains. $G_{0}$ started to decrease again at relatively high $\mathrm{IEI}_{12 \mathrm{~K}}$ concentrations, when the molar fraction of $\mathrm{IEI}_{12 \mathrm{~K}}$ in the hybrid micelles (defined as $2 n_{\text {IEI12k }} /\left(2 n_{\text {IEI12k }}+2 n_{\text {tPEO35k }}\right)$ assuming that the PIEA and PMEA blocks are homogeneously distributed in the cores of hybrid micelles) became larger than about $70-85 \mathrm{~mol} \%$, see Figure 3. This can be explained by the fact that at high IEI $_{12 K}$ concentrations an increasing fraction of micelles no longer contain sufficient number of tPEO chains to participate in the permanent tPEO network.

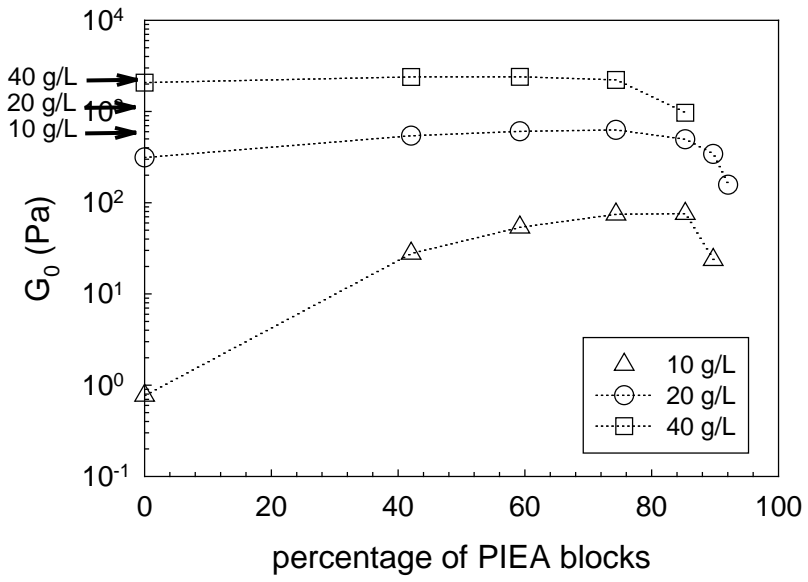

Figure 3. Evolution of the low frequency storage modulus (measured at $0.01 \mathrm{~Hz}$ ) as a function of the molar percentage of PIEA blocks in the micelle cores for $\mathrm{PEE}_{35 \mathrm{k}} / \mathrm{IEI}_{12 \mathrm{k}}$ hybrid hydrogels. The total concentration of block copolymer is indicated in the Figure. Dotted lines are guide to the eye. Arrows show the maximum moduli calculated assuming rubber elasticity and affine deformation.

The non-linear rheological properties of the cross-linked hydrogels were assessed using two kinds of measurements. First, $G^{\prime}$ and $G^{\prime \prime}$ were measured for $\mathrm{tPEO}_{12 \mathrm{k}} / \mathrm{IEI}_{12 \mathrm{~K}}$ mixtures as a function of the applied strain after in situ photo-cross-linking at $1 \mathrm{~Hz}$. Notice that the dynamic crosslinks of these mixtures were fully relaxed at this frequency. As expected, at constant copolymer concentration, substituting covalent links by dynamic ones led to a decrease of $G^{\prime}$ and an increase of the fracture strain (Figure S11). Figure 4a shows that if the amount of IEI $_{12 \mathrm{~K}}$ was increased while keeping the $\mathrm{tPEO}_{12 \mathrm{k}}$ concentration constant, not only $G_{0}$ increased as discussed above, but also the fracture strain in- 
creased. In common covalent hydrogels, increasing the number of elastically active chains increases $G_{0}$, but decreases the fracture strain $^{37}$. Kean et al. ${ }^{44}$ showed that adding very dynamic crosslinks in a covalent organogel improved the toughness but did not enhance $G_{0}$. Here, a synergetic effect was observed not only for the stiffness (increase of elastic modulus) but also for the nonlinear properties of the hydrogels (increase of the toughness).

Uniaxial stretching experiments were used to assess the evolution of the tensile stress with increasing strain (Figure 4b-c). As expected, gels obtained from $\mathrm{PPEO}_{35 \mathrm{k}}$ exhibited larger extensibility than those obtained from $\mathrm{tPEO}_{12 \mathrm{k}}$ with the same elastic modulus, because the elastically active chains are longer and thus more extensible. The effect of adding IEI ${ }_{12 \mathrm{~K}}$ was to substantially increase the strain at breakage (up to 350\%) without reducing the Young modulus thus corroborating the large oscillation amplitude measurements. The better resistance of hybrid hydrogels to fracture can be explained by a higher capacity to dissipate energy when mechanical strain is applied, because the dynamic network can rearrange and thereby prevent stress concentration at the vicinity of the broken permanent chains. A cyclic loadingunloading experiment (Figure S12) showed small hysteresis implying that dynamic rearrangement and the stress reduction was quite fast compared to the macroscopic loading rate ${ }^{44}$.
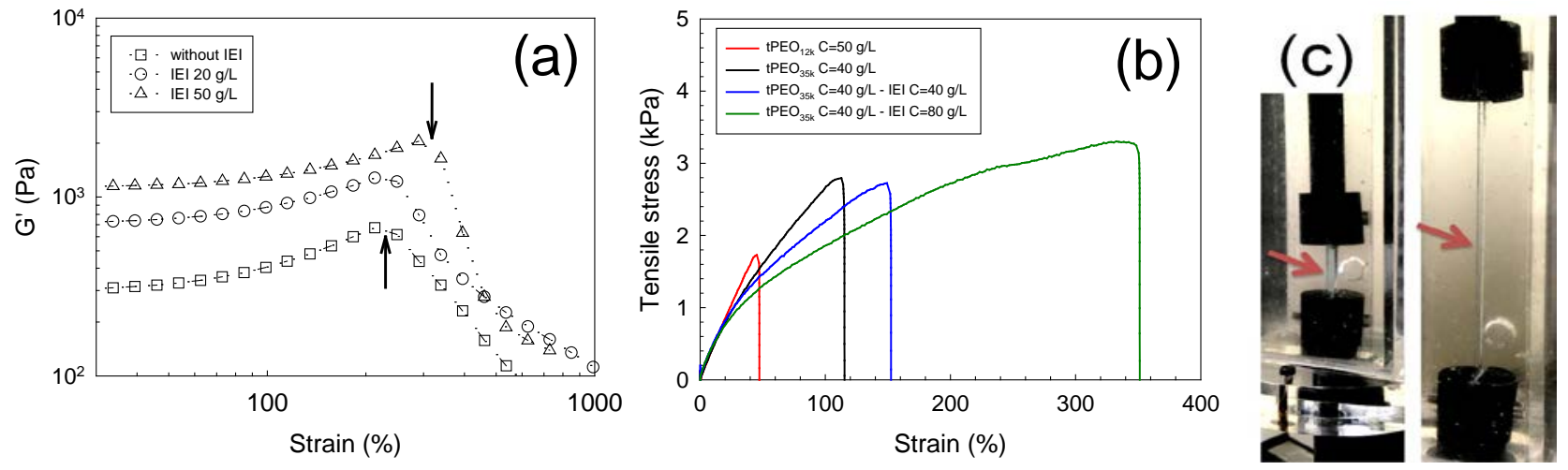

Figure 4. (a) Strain dependence of the elastic modulus $\left(G^{\prime}\right)$ measured at $f=1 \mathrm{~Hz}$ for $\mathrm{tPEO}_{12 \mathrm{k}} / \mathrm{IEI}_{12 \mathrm{~K}}$ hybrid photo-cross-linked hydrogels at constant $\mathrm{PEO}$ concentration $(C=30 \mathrm{~g} / \mathrm{L})$ and increasing concentration of $\mathrm{IEI}_{12 \mathrm{~K}}$ as indicated in the Figure. Arrows indicate the breakage of the sample. (b) Tensile tests of tPEO based hydrogels after photo-cross-linking (stretch rate $v=0.03 \mathrm{~s}^{-1}$ ). $(\mathbf{c}) \mathrm{Tensile} \mathrm{test} \mathrm{of} \mathrm{tPEO}_{35 \mathrm{k}}$ $C=40 \mathrm{~g} / \mathrm{L}-\mathrm{IEI}_{12 \mathrm{~K}} C=80 \mathrm{~g} / \mathrm{L}$ at the beginning (left) and end (right) of the test.

To conclude, we present here a novel type of hydrogel formed by self-assembly of two types of POE-based triblock copolymers of which one is photo-cross-linkable. The novelty is that the same junction zones contain both dynamic and covalent crosslinks. Formation of hybridized micellar cores before irradiation was confirmed by the evolution of the characteristic relaxation time of a single relaxation mode with the composition of the copolymer mixtures. Photo-cross-linking of the copolymer mixtures at thermodynamic equilibrium very rapidly turned the physical (and potentially injectable) hydrogel into a self-standing covalent hydrogel formed by one of the copolymers with the other remaining dynamic. The coexistence of both dynamic and covalent crosslinks in the same junctions led to synergetic effects that enhanced the elastic modulus and the resistance of the gels to fracture. These block copolymer based hydrogels are noncytotoxic $^{45}$ and could be interesting candidates for utilization as injectable and in situ photo-cross-linkable scaffolds for tissue engineering.

\section{ASSOCIATED CONTENT}

\section{Supporting Information}

Materials and methods. Structure of tPEO/IEI ${ }_{12 K}$ mixtures. Rheological properties of tPEO/IEI ${ }_{12 \mathrm{~K}}$ mixtures before photo-crosslinking. Photo-cross-linked hybrid covalent/dynamic hydrogels.

The Supporting Information is available free of charge on the ACS Publications website. brief description (PDF).

\section{AUTHOR INFORMATION}

\section{Corresponding Author}

Correspondence should be addressed to Erwan Nicol. Erwan.nicol@univ-lemans.fr. Phone: ++33.2.43.83.33.62 


\section{Author Contributions}

The manuscript was written through contributions of all authors. All authors have given approval to the final version of the manuscript. All authors contributed equally.

\section{Notes}

The authors declare no competing financial interests.

\section{ACKNOWLEDGMENT}

The authors acknowledge Maëva Robin and Arlette Tachou for their help during the block copolymers synthesis, Boris Jacquette for the SEC characterizations and Corentin Jacquemmoz for the NMR experiments.

This work was partially supported by the Région des Pays de la Loire - Bioregate Cluster (project Hydrophobiq).

\section{REFERENCES}

(1) T. Garg, O. Singh, S. Arora and R. S. R. Murthy. Scaffold: A Novel Carrier for Cell and Drug Delivery. Critical Reviews in Therapeutic Drug Carrier Systems 2012, 29, 1-63.

(2) M. Goldberg, R. Langer and X. Q. Jia. Nanostructured materials for applications in drug delivery and tissue engineering. Journal of Biomaterials Science-Polymer Edition 2007, 18, 241-268.

(3) W. R. Gombotz and D. K. Pettit. BIODEGRADABLE POLYMERS FOR PROTEIN AND PEPTIDE DRUG-DELIVERY. Bioconjugate Chemistry 1995, 6, 332-351.

(4) J. Jagur-Grodzinski. Polymeric gels and hydrogels for biomedical and pharmaceutical applications. Polymers for Advanced Technologies 2010, 21, 27-47.

(5) B. Jeong, S. W. Kim and Y. H. Bae. Thermosensitive sol-gel reversible hydrogels. Advanced Drug Delivery Reviews 2002, 54, 37-51.

(6) C. C. Lin and K. S. Anseth. PEG Hydrogels for the Controlled Release of Biomolecules in Regenerative Medicine. Pharmaceutical Research 2009, 26, 631-643.

(7) I. Roy and M. N. Gupta. Smart polymeric materials: Emerging biochemical applications. Chemistry \& Biology 2003, 10, 1161-1171.

(8) B. V. Slaughter, S. S. Khurshid, O. Z. Fisher, A. Khademhosseini and N. A. Peppas. Hydrogels in Regenerative Medicine. Advanced Materials 2009, 21, 3307-3329.

(9) M. W. Tibbitt, J. E. Dahlman and R. Langer. Emerging Frontiers in Drug Delivery. Journal of the American Chemical Society 2016, 138, 704717.

(10) T. R. Hoare and D. S. Kohane. Hydrogels in drug delivery: Progress and challenges. Polymer 2008, 49, 1993-2007.

(11) J. L. Drury and D. J. Mooney. Hydrogels for tissue engineering: scaffold design variables and applications. Biomaterials 2003, 24, 4337 4351.

(12) J. Elisseeff. Injectable cartilage tissue engineering. Expert Opinion on Biological Therapy 2004, 4, 1849-1859.

(13) N. E. Fedorovich, J. Alblas, J. R. de Wijn, W. E. Hennink, A. J. Verbout and W. J. A. Dhert. Hydrogels as extracellular matrices for skeletal tissue engineering: state-of-the-art and novel application in organ printing. Tissue Engineering 2007, 13, 1905-1925.

(14) H. Geckil, F. Xu, X. H. Zhang, S. Moon and U. Demirci. Engineering hydrogels as extracellular matrix mimics. Nanomedicine 2010, 5, 469-484.

(15) A. S. Hoffman. Hydrogels for biomedical applications. Advanced Drug Delivery Reviews 2002, 54, 3-12.

(16) D. W. Hutmacher. Scaffolds in tissue engineering bone and cartilage. Biomaterials 2000, 21, 2529-2543.

(17) J. L. Ifkovits and J. A. Burdick. Review: Photopolymerizable and degradable biomaterials for tissue engineering applications. Tissue Engineering 2007, 13, 2369-2385.

(18) P. B. Malafaya, G. A. Silva and R. L. Reis. Natural-origin polymers as carriers and scaffolds for biomolecules and cell delivery in tissue engineering applications. Advanced Drug Delivery Reviews 2007, 59, $207-$ 233.
(19) J. F. Mano, G. A. Silva, H. S. Azevedo, P. B. Malafaya, R. A. Sousa, S. S. Silva, L. F. Boesel, J. M. Oliveira, T. C. Santos, A. P. Marques, N. M. Neves and R. L. Reis. Natural origin biodegradable systems in tissue engineering and regenerative medicine: present status and some moving trends. Journal of the Royal Society Interface 2007, 4, 999-1030.

(20) M. S. Shoichet. Polymer Scaffolds for Biomaterials Applications. Macromolecules 2010, 43, 581-591.

(21) A. C. Jen, M. C. Wake and A. G. Mikos. Review: Hydrogels for cell immobilization. Biotechnology and Bioengineering 1996, 50, 357364.

(22) K. Knop, R. Hoogenboom, D. Fischer and U. S. Schubert. Poly(ethylene glycol) in Drug Delivery: Pros and Cons as Well as Potential Alternatives. Angewandte Chemie-International Edition 2010, 49, 6288-6308.

(23) C. W. Peak, J. J. Wilker and G. Schmidt. A review on tough and sticky hydrogels. Colloid and Polymer Science 2013, 291, 2031-2047.

(24) K. Ito. Novel cross-linking concept of polymer network: Synthesis, structure, and properties of slide-ring gels with freely movable junctions. Polymer Journal 2007, 39, 489-499.

(25) D. Myung, D. Waters, M. Wiseman, P.-E. Duhamel, J. Noolandi, C. N. Ta and C. W. Frank. Progress in the development of interpenetrating polymer network hydrogels. Polymers for Advanced Technologies 2008, 19, 647-657.

(26) L. H. Sperling and V. Mishra. The current status of interpenetrating polymer networks. Polymers for Advanced Technologies 1996, 7, 197208.

(27) J. P. Gong. Why are double network hydrogels so tough? Soft Matter 2010, 6, 2583-2590.

(28) J. P. Gong, Y. Katsuyama, T. Kurokawa and Y. Osada. Doublenetwork hydrogels with extremely high mechanical strength. Advanced Materials 2003, 15, 1155-1158.

(29) Y. Tanaka, J. P. Gong and Y. Osada. Novel hydrogels with excellent mechanical performance. Progress in Polymer Science 2005, 30, 1-9.

(30) K. Haraguchi. Nanocomposite hydrogels. Current Opinion in Solid State \& Materials Science 2007, 11, 47-54.

(31) K. Haraguchi and T. Takehisa. Nanocomposite hydrogels: A unique organic-inorganic network structure with extraordinary mechanical, optical, and swelling/de-swelling properties. Advanced Materials 2002, 14, 1120-1124.

(32) T. Matsunaga, T. Sakai, Y. Akagi, U. Chung and M. Shibayama. Structure Characterization of Tetra-PEG Gel by Small-Angle Neutron Scattering. Macromolecules 2009, 42, 1344-1351.

(33) T. Sakai, T. Matsunaga, Y. Yamamoto, C. Ito, R. Yoshida, S. Suzuki, N. Sasaki, M. Shibayama and U.-i. Chung. Design and Fabrication of a High-Strength Hydrogel with Ideally Homogeneous Network Structure from Tetrahedron-like Macromonomers. Macromolecules 2008, 41, 5379-5384.

(34) T. Nicolai, O. Colombani and C. Chassenieux. Dynamic polymeric micelles versus frozen nanoparticles formed by block copolymers. Soft Matter 2010, 6, 3111-3118.

(35) M. A. Winnik and A. Yekta. Associative polymers in aqueous solution. Current Opinion in Colloid \& Interface Science 1997, 2, 424-436.

(36) C. Chassenieux and C. Tsitsilianis. Recent trends in $\mathrm{pH} /$ thermoresponsive self-assembling hydrogels: from polyions to peptide-based polymeric gelators. Soft Matter 2016, 12, 1344-1359.

(37) V. Kadam, T. Nicolai, E. Nicol and L. Benyahia. Structure and Rheology of Self-Assembled Telechelic Associative Polymers in Aqueous Solution before and after Photo-Cross-Linking. Macromolecules 2011, 44, 8225-8232.

(38) N. Sanabria-DeLong, A. J. Crosby and G. N. Tew. Photo-CrossLinked PLA-PEO-PLA Hydrogels from Self-Assembled Physical Networks: Mechanical Properties and Influence of Assumed Constitutive Relationships. Biomacromolecules 2008, 9, 2784-2791.

(39) R. Tamate, T. Ueki, Y. Kitazawa, M. Kuzunuki, M. Watanabe, A. M. Akimoto and R. Yoshida. Photo-Dimerization Induced Dynamic Viscoelastic Changes in ABA Triblock Copolymer-Based Hydrogels for 3D Cell Culture. Chemistry of Materials 2016, 28, 6401-6408.

(40) A. Klymenko, T. Nicolai, L. Benyahia, C. Chassenieux, O. Colombani and E. Nicol. Multiresponsive Hydrogels Formed by Interpenetrated Self-Assembled Polymer Networks. Macromolecules 2014, 47, 8386-8393. 
(41) V. S. Kadam, E. Nicol and C. Gaillard. Synthesis of Flower-Like Poly(Ethylene Oxide) Based Macromolecular Architectures by PhotoCross-Linking of Block Copolymers Self-Assemblies. Macromolecules 2012, 45, 410-419.

(42) E. Nicol, T. Derouineau, F. Puaud and A. Zaitsev. Synthesis of double hydrophilic poly(ethylene oxide)-b-poly(2-hydroxyethyl acrylate) by single-electron transfer-living radical polymerization. Journal of Polymer Science Part A: Polymer Chemistry 2012, 50, 3885-3894.

(43) E. Nicol and R.-P. Nzé. Supplemental Activator and Reducing Agent Atom Transfer Radical Polymerization of 2-Hydroxyethyl Acrylate from High Molar Mass Poly(ethylene oxide) Macroinitiator in Dilute Solution. Macromolecular Chemistry and Physics 2015, 216, 1405-1414.

(44) Z. S. Kean, J. L. Hawk, S. Lin, X. Zhao, R. P. Sijbesma and S. L. Craig. Increasing the Maximum Achievable Strain of a Covalent Polymer Gel Through the Addition of Mechanically Invisible Cross-Links. Advanced Materials 2014, 26, 6013-6018.

(45) A. Klymenko, T. Nicolai, C. Chassenieux, O. Colombani and E. Nicol. Formation of porous hydrogels by self-assembly of photo-crosslinkable triblock copolymers in the presence of homopolymers. Polymer 2016, 106, 152-158. 
SYNOPSIS TOC.
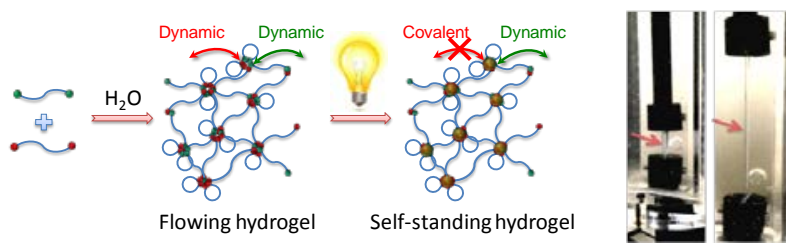


\section{Supporting Information}

\section{Photo-Cross-Linked Self-Assembled Poly(Ethylene}

\section{Oxide) Based Hydrogels Containing Hybrid}

\section{Junctions with Dynamic and Permanent Crosslinks}

Erwan Nicol ${ }^{a, *}$, Taco Nicolai ${ }^{a}$, Jingwen Zhao ${ }^{b}$, Tetsuharu Narita ${ }^{b, c}$

a IMMM - UMR CNRS 6283, Le Mans Université, avenue O. Messiaen, 72085 Le Mans cedex

9, France

b Laboratoire Sciences et Ingénierie de la Matière Molle, ESPCI Paris, PSL University, Sorbonne Université, CNRS, 75005 Paris, France

c Global Station for Soft Matter, Global Institution for Collaborative Research and Education, Hokkaido University, Sapporo, Japan

\section{CONTENTS}

Materials and methods:

Block copolymer synthesis and characterization

P. 3

Figure S1

P. 4

Sample preparation

P. 4

Experimental methods

P. 5

Structure of tPEO/IEI mixtures

P. 6

Figure S2

P. 7

Figure S3

P. 7

Rheological properties of tPEO/IEI mixtures before photo-cross-linking

P. 8 
$\begin{array}{ll}\text { Figure S4 } & \text { P. } 8\end{array}$

$\begin{array}{ll}\text { Figure S5 } & \text { P. } 9\end{array}$

$\begin{array}{ll}\text { Figure S6 } & \text { P. } 10\end{array}$

$\begin{array}{ll}\text { Photo-cross-linked hybrid covalent/dynamic hydrogels } & \text { P. } 11\end{array}$

$\begin{array}{ll}\text { Figure S7 } & \text { P. } 11\end{array}$

$\begin{array}{ll}\text { Figure S8 P. } 11 & \text { P }\end{array}$

$\begin{array}{ll}\text { Figure S9 } & \text { P. } 12\end{array}$

$\begin{array}{ll}\text { Figure S10 P. } 12 & \end{array}$

$\begin{array}{ll}\text { Figure S11 P. } 13 & \text { P. }\end{array}$

$\begin{array}{ll}\text { Figure S12 P. } 13 & \text { P }\end{array}$

$\begin{array}{lr}\text { References } & \text { P. } 14\end{array}$ 


\section{Materials and Methods}

\section{Block copolymers synthesis}

Amphiphilic triblock copolymers were synthesized according to already published procedures ${ }^{1-4}$. Briefly, a triple hydrophilic poly(2-hydroxyethyl acrylate)-b-poly(ethylene oxide)b-poly(2-hydroxyethyl acrylate), PHEA-b-PEO-b-PHEA, was synthesized by growing two PHEA blocks from a dibrominated PEO (Br-PEO-Br) macroinitiator using SARA-ATRP. In the case of $\mathrm{PEO}_{12 \mathrm{k}}$ of $\mathrm{M}_{\mathrm{n}}=12000 \mathrm{~g} / \mathrm{mol}$, the synthesis was performed in $\mathrm{DMSO}^{3}$ with a molar ratio [Br-PEO-Br] $/[\mathrm{HEA}] /\left[\mathrm{Me}_{6} \mathrm{TREN}\right] /\left[\mathrm{CuBr}_{2}\right]$ : 1/8/0.2/0.05. Copper wire was used as a catalyst. Prior to use the copper surface was activated with sulfuric acid. A degree of polymerization of 7 for the PHEA blocks was obtained at $90 \%$ conversion. In the case of $\mathrm{PEO}_{35 \mathrm{k}}$ of $\mathrm{M}_{\mathrm{n}}=35000$ $\mathrm{g} / \mathrm{mol}$, the synthesis was performed in water ${ }^{4}$ with a molar ratio [Br-PEO$\mathrm{Br}] /[\mathrm{HEA}] /\left[\mathrm{Me}_{6} \mathrm{TREN}\right] /[\mathrm{CuBr}] /\left[\mathrm{CuBr}_{2}\right]: 1 / 10 / 0.5 / 0.3 / 0.2$. A degree of polymerization of 9 for the PHEA blocks was obtained at $90 \%$ conversion. Polymerizable methacrylate functions were then grafted onto the PHEA-blocks leading to the UV-crosslinkable hydrophobic poly(methacryloyloxyethyl acrylate) (PMEA) blocks. ${ }^{1} \mathrm{H}$ NMR analysis of both final PMEA-bPEO-b-PMEA (tPEO) triblock copolymers indicated a quantitative functionalization of the HEA units into methacryloyloxyethyl acrylate ones. The number $\left(\mathrm{M}_{\mathrm{n}}\right)$ and weight $\left(\mathrm{M}_{\mathrm{w}}\right)$ average molar mass and dispersity $\left(\mathrm{D}=\mathrm{M}_{\mathrm{w}} / \mathrm{M}_{\mathrm{n}}\right.$ ) were determined by Size Exclusion Chromatography (SEC) in THF using light scattering and refractometric detection. $\mathrm{M}_{\mathrm{n}}=1.42 \times 10^{4} \mathrm{~g} / \mathrm{mol}, \mathrm{M}_{\mathrm{w}}=1.59 \times 10^{4}$ $\mathrm{g} / \mathrm{mol}, \mathrm{D}=1.1$ were measured for $\mathrm{tPEO}_{12 \mathrm{k}} . \mathrm{M}_{\mathrm{n}}=4.21 \times 10^{4} \mathrm{~g} / \mathrm{mol}, \mathrm{M}_{\mathrm{w}}=5.53 \times 10^{4} \mathrm{~g} / \mathrm{mol}, \mathrm{D}=1.3$ were measured for $\mathrm{HPO}_{35 \mathrm{k}}$.

Poly(isobutyryloxyethyl acrylate)-b-poly(ethylene oxide)-b-poly(isobutyryloxyethyl acrylate) (PIEA-b-PEO-b-PIEA: IEI) was synthesized by esterification of PHEA-b-PEO ${ }_{12 \mathrm{k}}$-b-PHEA with isobutyryl chloride in the presence of triethylamine and DMPA using the same procedure as that used for synthetizing PMEA-b-PEO-b-PMEA ${ }^{1,5} .{ }^{1} \mathrm{H}$ NMR analysis of the resulting IEI triblock copolymer indicated $85 \%$ of functionalization of the HEA units into isobutyryloxyethyl acrylate ones (Figure S1). The hydrophobic block was thus a statistical copolymer poly((isobutyryloxyethyl acrylate) ${ }_{0.85}$-co-(2-hydroxyethyl acrylate) 0.15 ). $\mathrm{M}_{\mathrm{n}}=1.42 \times 10^{4} \mathrm{~g} / \mathrm{mol}$, $\mathrm{M}_{\mathrm{w}}=1.59 \times 10^{4} \mathrm{~g} / \mathrm{mol}, \mathrm{D}=1.1$ were measured by multi-detection SEC. 

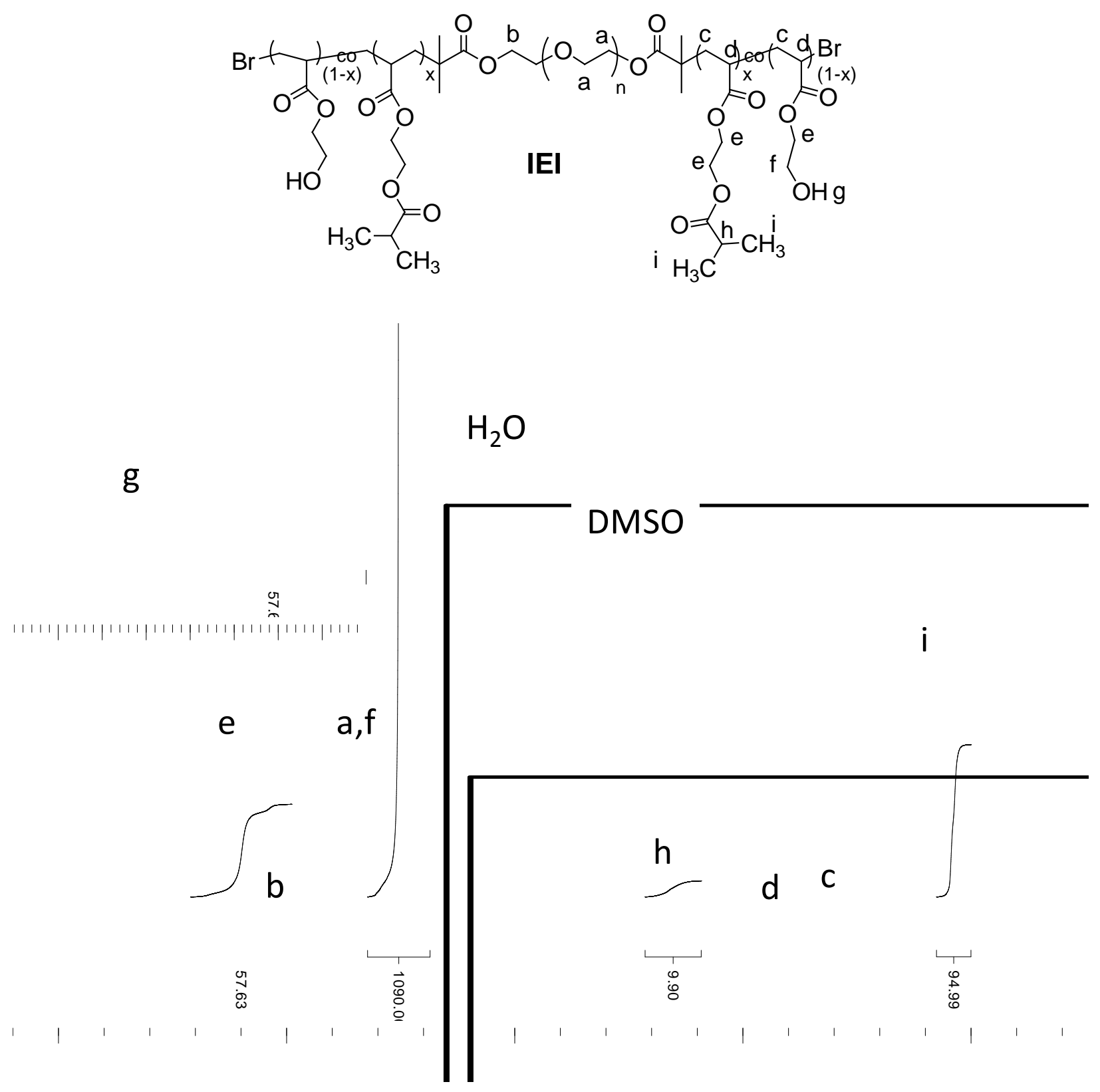

Figure S1. ${ }^{1} \mathrm{H}$ NMR of PIEA- $b$-PEO- $b$-PIEA (IEI) copolymer in DMSO-d6 ( $\left.v_{0}=400 \mathrm{MHz}\right)$

\section{Sample preparation}

Stock solutions of tPEO were prepared by dissolving the polymer powder in deionized water (MilliPore) and stored at $4{ }^{\circ} \mathrm{C}$. For photo-cross-linking experiments a solution of 2,2-dimethoxy2-phenylacetophenone (DMPA) photoinitiator (0.01 M) was prepared in THF. The required amount of solution of DMPA was placed on the walls of a glass vial, and THF was evaporated under a gentle flow of argon. Then, the polymer dissolved in deionized Milli-Q water was 
introduced into a vial that was sealed with a rubber septum. The vial was rotated overnight on a roller stirrer. The quantity of DMPA was fixed to around 10 molecules per micelle considering the average aggregation number determined below.

\section{Methods}

Oscillatory shear measurements were done with a stress-controlled rheometer MCR-301 (Anton Paar) equipped with a cone and plate geometry (gap $0.103 \mathrm{~mm}$, diameter $25 \mathrm{~mm}$ ). For insitu cross-linking, the samples were degassed in advance and introduced into the rheometer under gentle flow of argon. In order to prevent evaporation, the geometry was covered with silicon oil. The samples were irradiated by a UV light (Dymax Bluewave-200 lamp) at 365nm under air with an intensity $0.17 \mathrm{~W} . \mathrm{cm}^{-1}$ during $60 \mathrm{~s}$. The measurements were done in the linear response regime unless otherwise specified.

Static and dynamic light scattering measurements were done using a commercial static and dynamic light scattering equipment (ALV-Langen, Germany and LS-Instruments, Switzerland) operating with a vertically polarized laser with wavelength $\lambda=632 \mathrm{~nm}$. The measured scattered light intensity was corrected for that of the solvent and normalized by that of toluene. The relative excess scattering intensity $\left(\mathrm{I}_{\mathrm{r}}\right)$ was multiplied with the Rayleigh factor of toluene and expressed in units of $\mathrm{cm}-1$. The measurements were done at $20{ }^{\circ} \mathrm{C}$ using a thermostated bath over a range of scattering wave vectors $(q=4 . \pi \cdot n \cdot \sin (\theta / 2) / \lambda)$, with $\theta$ the angle of observation and $\mathrm{n}$ the refractive index of the solvent). The electric field autocorrelation function (g1(t)) was calculated from the normalized intensity autocorrelation functions $(\mathrm{g} 2(\mathrm{t}))$ : $\mathrm{g} 2(\mathrm{t})=1+\mathrm{g} 1(\mathrm{t})^{2}$ and was analyzed in terms of a relaxation time distribution:

$$
g_{1}(t)=\int A(\log \tau) \exp (-t / \tau) d \log \tau
$$

At low polymer concentration a single relaxation mode was observed, but at higher concentrations a second slower and broader relaxation mode was observed. All correlation functions could be well-described using a log-normal distribution for the fast mode and a generalized exponential for the slow mode:

$$
A(\log \tau)=k \tau^{p} \exp \left\lfloor-\left(\tau / \tau^{*}\right)^{s}\right\rfloor
$$


The average relaxation rates $\left(\Gamma=<\tau^{-1}>\right)$ of the single mode at low concentrations and of the fast mode at high concentrations were found to be $\mathrm{q}^{2}$-dependent and the cooperative diffusion coefficient was calculated as

$$
\mathrm{Dc}=\Gamma \cdot \mathrm{q}^{-2}
$$

The large deformation behavior of the gels was studied by uniaxial tensile and loadingunloading tests on an Instron 5565 tensile tester with a $10 \mathrm{~N}$ load cell. Samples were rectangular in shape with $5 \mathrm{~mm}$ width, $3 \mathrm{~mm}$ thickness, and $20 \mathrm{~mm}$ length (length between clamps). We kept the samples in paraffin oil during all the tests to prevent them from drying.

\section{Structure of tPEO/IEI mixtures}

The structure of self-assemblies formed by PMEA-b-PEO-b-PMEA (tPEO) and PIEA-b-PEO-bPIEA (IEI) triblock copolymers were studied individually and in mixtures. The apparent molar mass $\left(\mathrm{M}_{\mathrm{a}}\right)$ and hydrodynamic radius $\left(\mathrm{R}_{\mathrm{ha}}\right)$ of individual tPEO ${ }_{12 \mathrm{k}}$ and IEI aggregates were obtained by static and dynamic light scattering as described in the materials and methods section and are shown as a function of the polymer concentration in Figure S2. As was already reported observed for similar systems in the literature ${ }^{2,6} M_{a}$ and $R_{\text {ha }}$ increased with increasing concentration due to the bridging of micelles leading to formation of larger aggregates. At high concentrations, $M_{a}$ decreased because repulsive interactions dominated ${ }^{6}$. The number of hydrophobic blocks per micellar core $\left(\mathrm{N}_{\mathrm{agg}}\right)$ could be estimated from $\mathrm{M}_{\mathrm{a}}$ measured at $1 \mathrm{~g} / \mathrm{L}$, because at this concentration, repulsive interactions between micelles were negligible and micelles were mainly in the form of single flowers ${ }^{1}$. $\mathrm{N}_{\mathrm{agg}} \approx 60$ was found for $\mathrm{tPEO}_{12 \mathrm{k}}$ micelles and $N_{\text {agg }} \approx 30$ for IEI $_{12 k}$ micelles. The large difference between $\mathrm{TPEO}$ and IEI is probably due to the lower hydrophobicity of the PIEA blocks which contained about $15 \%$ residual hydrophilic units whereas PMEA blocks did not. $\mathrm{N}_{\mathrm{agg}}$ of $\mathrm{tPEO}_{35 \mathrm{k}}$ was also approximately 30 (Figure S3). 

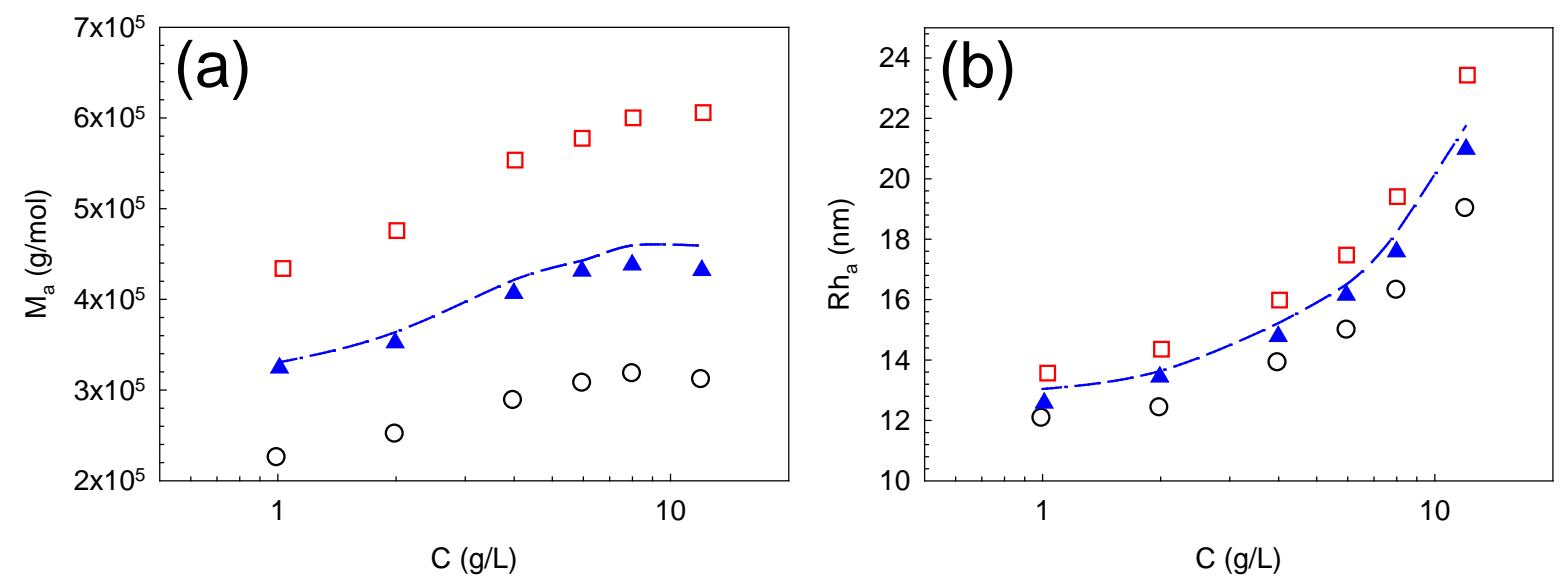

Figure S2. Concentration dependences of (a) the apparent molar mass $\left(\mathrm{M}_{\mathrm{a}}\right)$ and (b) the apparent hydrodynamic radius $\left(\mathrm{Rh}_{\mathrm{a}}\right)$ for the IEI aggregates (open circles), $\mathrm{tPEO}_{12 \mathrm{k}}$ (open squares) and $\mathrm{tPEO}_{12 \mathrm{k}} / \mathrm{IEI}$ 50/50 (\%v/v) mixtures (filled triangles). Blue dashed lines represent the theoretical evolution of non-hybridizing aggregates mixture (equation (3) and (4)).

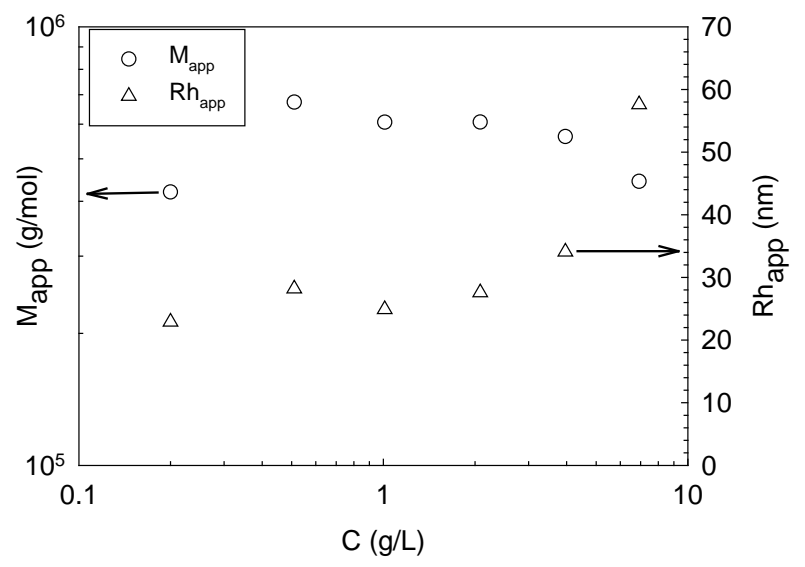

Figure S3. Concentration dependence of the apparent molar mass and apparent hydrodynamic radius of $\mathrm{tPEO}_{35 \mathrm{k}}$ aggregates in water.

The concentration dependences of $\mathrm{M}_{\mathrm{a}}$ and $\mathrm{Rh}_{\mathrm{a}}$ of $\mathrm{tPEO}_{12 \mathrm{k}} / \mathrm{IEI}$ 50/50 (vol/vol) mixtures are also shown in Figure S2. Note that all the mixtures formed homogenous transparent solutions. The same qualitative dependence was observed for the mixture and the individual systems. The 
experimental data were compared with calculated values of $\mathrm{M}_{\mathrm{a}}$ (weight-averaged) and $\mathrm{Rh}_{\mathrm{a}}(\mathrm{z}$ averaged) considering no interaction between $\mathrm{PEO}_{12 \mathrm{k}}$ and IEI in the mixture:

$$
\begin{aligned}
& M_{a}(m i x)=\frac{M_{a}(t P E O) \cdot C(t P E O)+M_{a}(I E I) \cdot C(I E I)}{C(t P E O)+C(I E I)} \\
& R h_{a}(m i x)=\left[\frac{M_{a}(t P E O) \cdot C(t P E O) \cdot\left[R h_{a}(t P E O)\right]^{-1}+M_{a}(I E I) \cdot C(I E I) \cdot\left[R h_{a}(I E I)\right]^{-1}}{M_{a}(t P E O) \cdot C(t P E O)+M_{a}(I E I) \cdot C(I E I)}\right]^{-1}
\end{aligned}
$$

The calculated values are close to the experimental data at low polymer concentrations where the effect of interaction is small. This suggests that either hybridization did not occur or that $\mathrm{N}_{\text {agg }}$ of the hybrid micelles was the same as the calculated average.

\section{Rheological properties of tPEO/IEI mixtures before photo-cross-linking}

The viscosity of individual systems and mixtures was measured as function of the shear rate. All solutions exhibited Newtonian behavior over large range of shear rates, but the most viscous solutions showed shear thinning at shear rates above $10 \mathrm{~s}^{-1}$ (see Fig S4a and S4b).
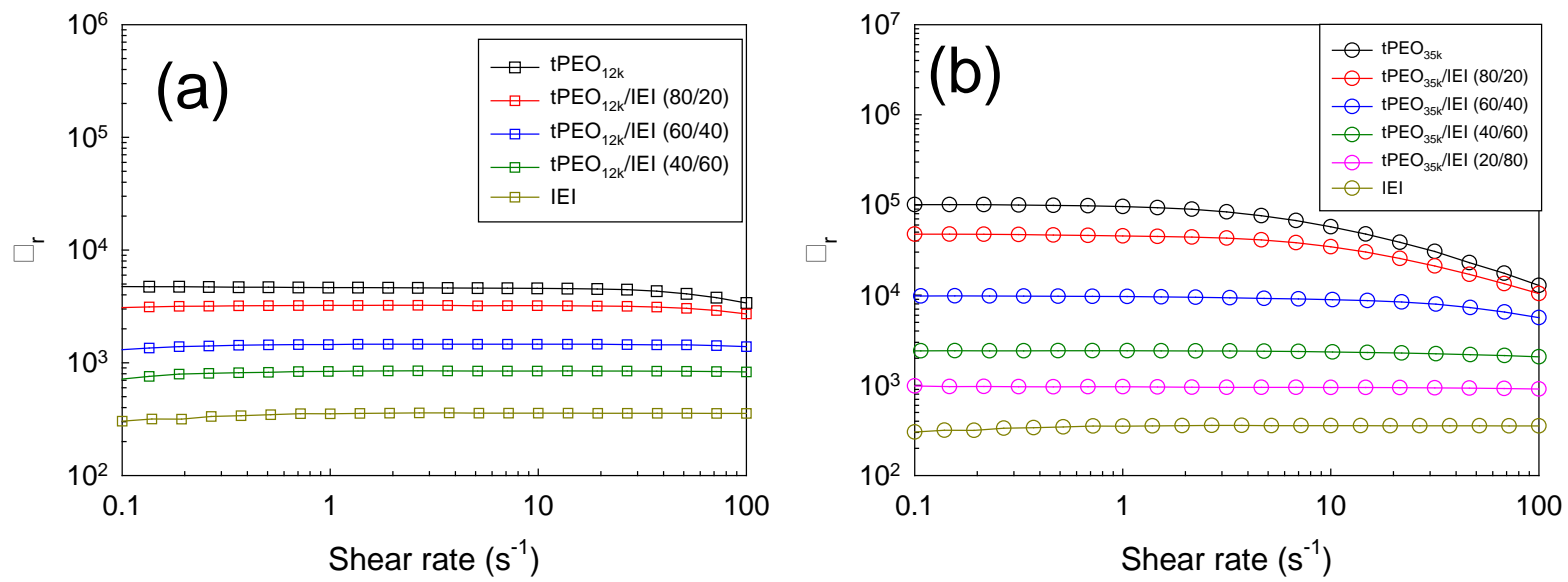

Figure S4. Shear rate dependence of the relative viscosity of (a) $\mathrm{tPEO}_{12 \mathrm{k}} / \mathrm{IEI}$ hybrid hydrogels at $\mathrm{C}=50$ g. $\mathrm{L}^{-1}$ and (b) $\mathrm{tPEO}_{35 \mathrm{k}} / \mathrm{IEI}$ hybrid hydrogels at $\mathrm{C}=50 \mathrm{~g} . \mathrm{L}^{-1}$

Individual triblock copolymer solutions showed a strong increase of the relative zero-shear viscosity $\left(\eta_{r}\right)$ with increasing concentration above a critical value $\left(C_{p}\right)$ (Figure $\left.S 5 a\right)$. The strong increase of $\eta_{r}$ was caused by formation of a transient network of bridged micelles and $C_{p}$ 
corresponds to the percolation threshold. We found $\mathrm{C}_{\mathrm{p}} \approx 15 \mathrm{~g} / \mathrm{L}$ for $\mathrm{tPEO}_{12 \mathrm{k}}$ and IEI and $\mathrm{C}_{\mathrm{p}} \approx 8$ $\mathrm{g} / \mathrm{L}$ for $\mathrm{tPEO}_{35 \mathrm{k}}$
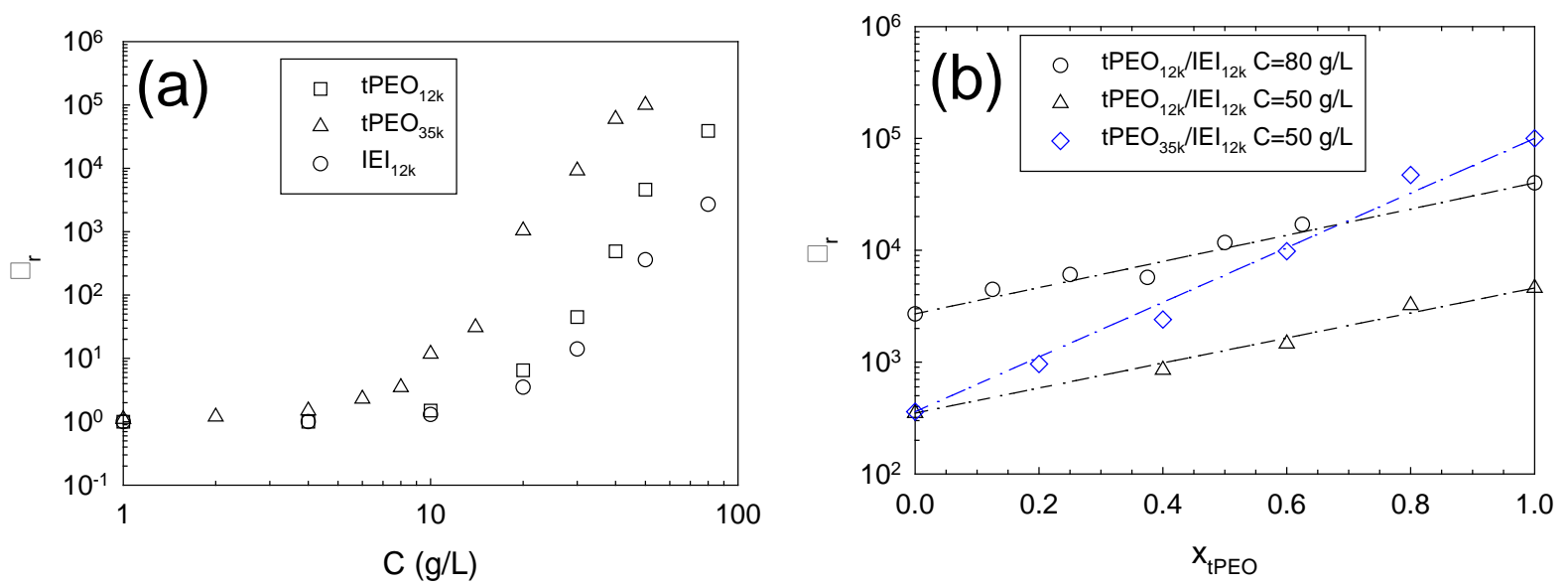

Figure S5. (a) Concentration dependence of the relative viscosity of $\mathrm{IEI}_{12 \mathrm{~K}}, \mathrm{tPEO}_{12 \mathrm{k}}$ and $\mathrm{tPEO}_{35 \mathrm{k}}$ at $\mathrm{T}=20^{\circ} \mathrm{C}$. (b) Evolution of the relative viscosity with the weight fraction of tPEO in tPEO/IEI mixtures at various concentrations. Dashed lines are fits to equation (5).

The viscosity of $\mathrm{tPEO}_{12 \mathrm{k}} / \mathrm{IEI}$ and $\mathrm{tPEO}_{35 \mathrm{k}} / \mathrm{IEI}$ mixtures was measured as a function of the composition $\mathrm{C}=50 \mathrm{~g} / \mathrm{L}$. In addition, $\mathrm{tPEO}_{12 \mathrm{k}} / \mathrm{IEI}$ mixtures were studied at $\mathrm{C}=80 \mathrm{~g} / \mathrm{L}$. The dependence of $\eta_{\mathrm{r}}$ on the weight fraction of $\operatorname{tPEO}(x)$ in the mixtures is shown in Fig. S5b. Interestingly, for a given $\mathrm{C}, \eta_{\mathrm{r}}$ had a logarithmic dependence on $x$ :

$$
\log \left(\eta_{r(h y b)}\right)=x_{t P E O} \cdot \log \left(\eta_{r(t P E O)}\right)+x_{I E I} \cdot \log \left(\eta_{r(I E I)}\right)
$$

This behavior noticeably differs from that exhibited by mixtures of other types of self-assembled triblock copolymers ${ }^{7,8}$. In the case of hydrophobically end-capped PEO, Annable et al. ${ }^{7}$ reported that chains with different end-cap alkyl lengths relaxed independently. This implies that the viscosity of the mixtures was governed by the polymers with the longest relaxation time, i.e. the highest viscosity. In the case of mixtures of $\mathrm{pH}$-sensitive amphiphilic triblock copolyelectrolytes the viscosity was also governed by that of the most viscous copolymer as soon as it formed a percolated network ${ }^{8}$. In this latter case, although the evolution of the viscosity was not strictly proportional to the evolution of the mean relaxation time $\tau$ (lifetime of a hydrophobic block in a micellar core), it followed the same tendency. 
The frequency dependence of the shear moduli was determined as a function of $x$. It showed a single relaxation mode that shifted to lower frequencies with increasing $x$, see Fig. S6.

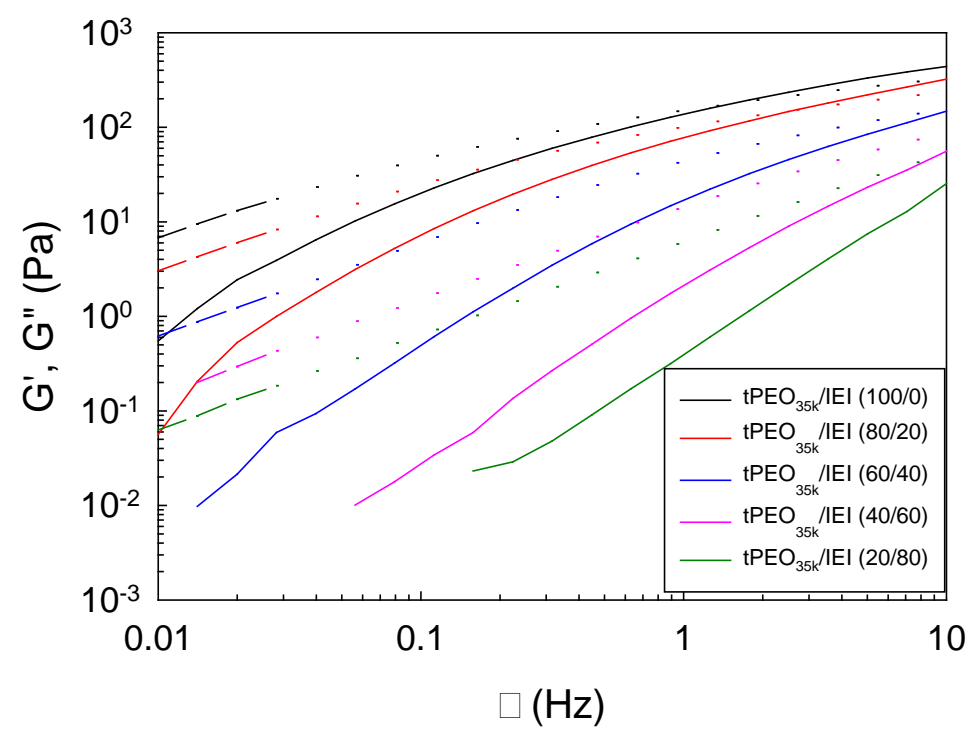

Figure S6. Frequency dependences of the storage $\left(G^{\prime}\right)$ and loss $\left(G^{\prime \prime}\right)$ moduli of tPEO${ }_{35 k} / \mathrm{IEI}$ mixtures at $\mathrm{C}_{\text {tot }}=50 \mathrm{~g} / \mathrm{L}$ and $\mathrm{T}=20{ }^{\circ} \mathrm{C}$. 
Photo-cross-linked hybrid covalent/dynamic hydrogels

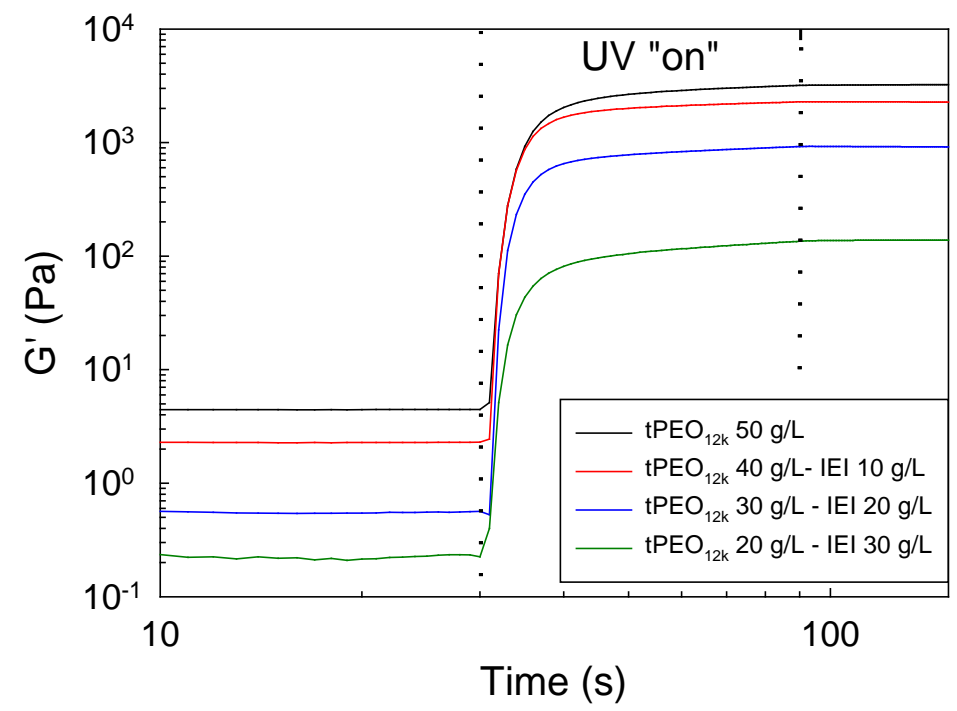

Figure S7. Evolution of the elastic modulus $\left(\mathrm{G}^{\prime}\right)$ during the photo-cross-linking step of $\mathrm{tPEO}_{12 \mathrm{k}} / \mathrm{IEI}$ hybrid hydrogels at constant polymer concentration $\mathrm{C}=50 \mathrm{~g} / \mathrm{L}(\gamma=2 \%, \mathrm{f}=1 \mathrm{~Hz})$

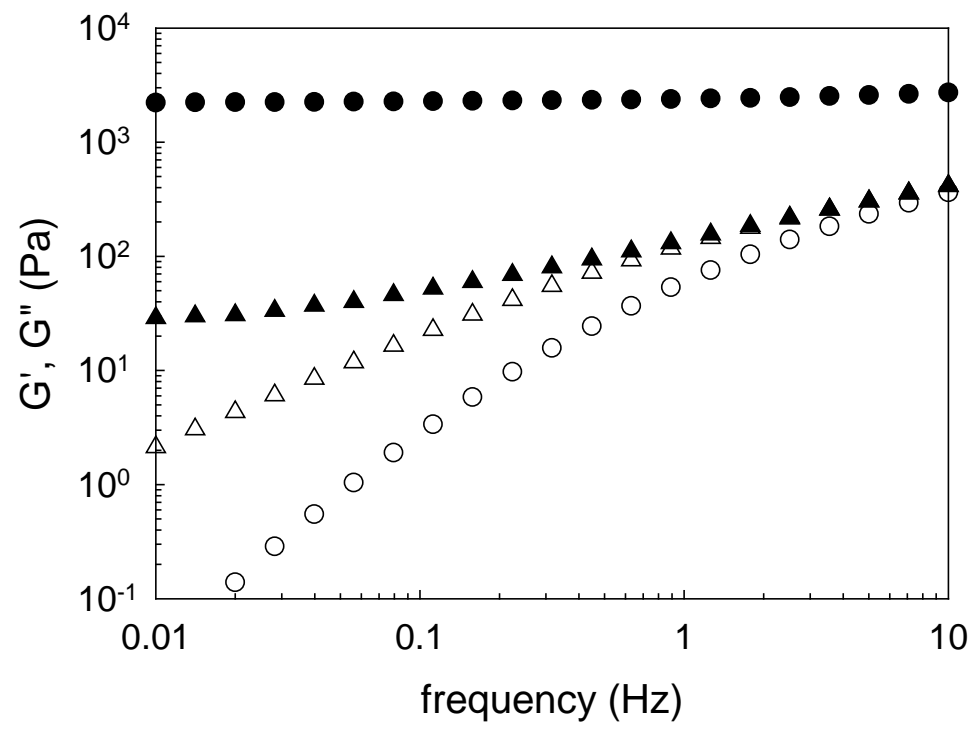

Figure S8. Frequency dependence of the storage (G', circles) and loss (G", triangles) moduli before (open symbols) and after UV-irradiation (filled symbols) of $\mathrm{tPEO}_{35 \mathrm{k}} / \mathrm{IEI}$ (40 g/L-40 g/L) mixture 


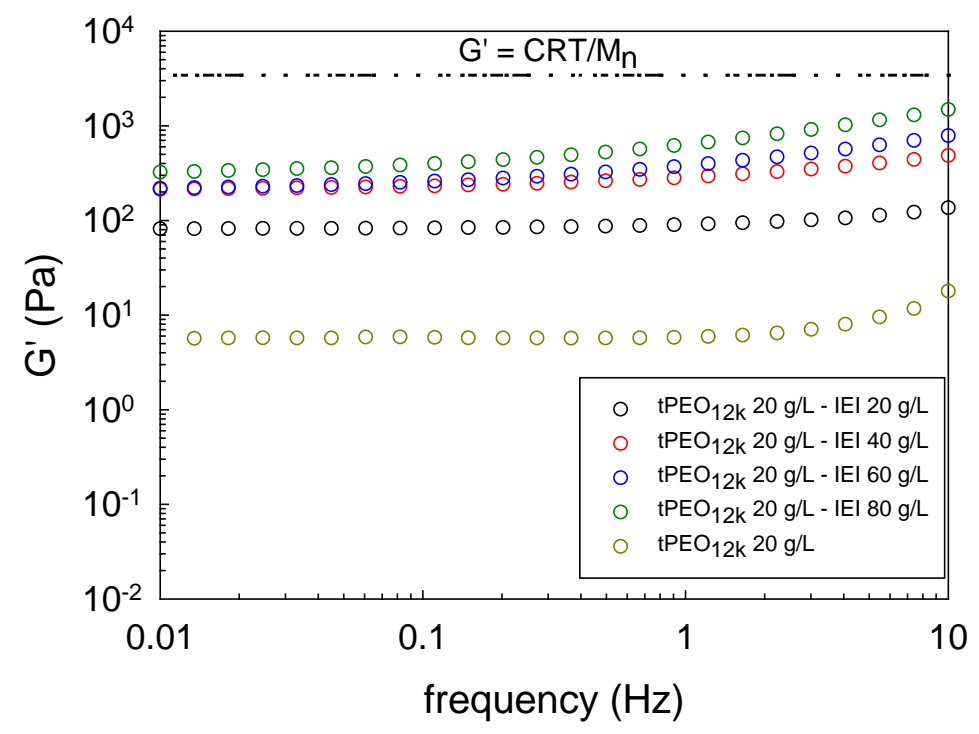

Figure S9. Frequency dependence of the storage modulus of photo-cross-linked hybrid $\mathrm{tPEO}_{12 \mathrm{k}} / \mathrm{IEI}$ for $\mathrm{C}_{\mathrm{tPEO} 12 \mathrm{k}}=20 \mathrm{~g} / \mathrm{L}$ and various concentration of IEI. The dashed line corresponds to the theoretical value of $\mathrm{G}^{\prime}$ using the affine model assuming that all the $\mathrm{PPEO}_{12 \mathrm{k}}$ chains are elastically active.

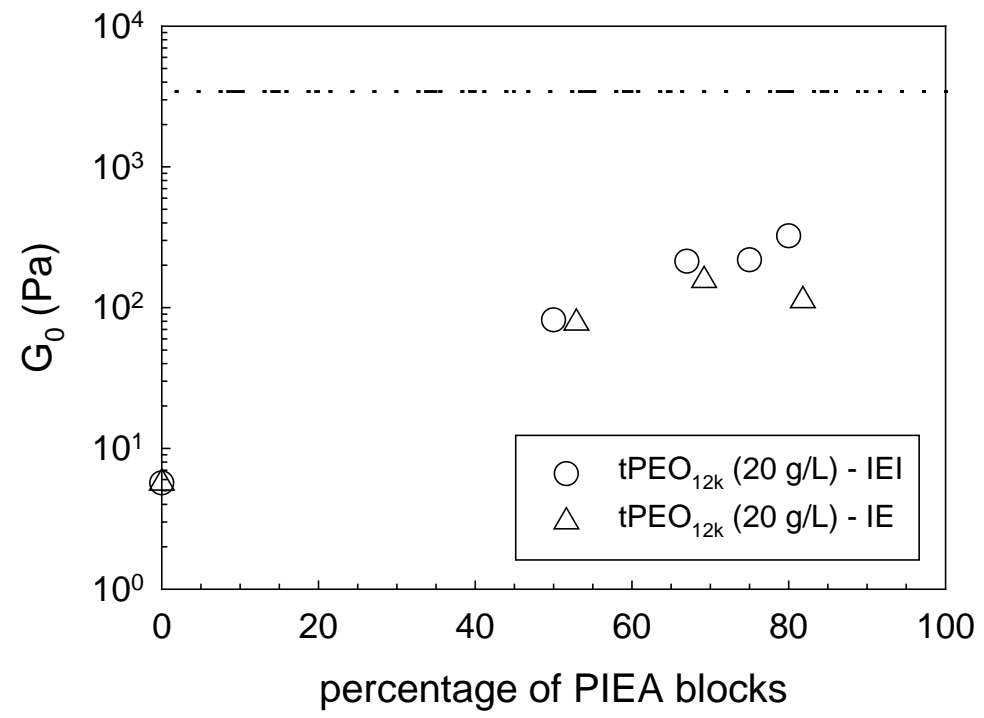

Figure S10. Evolution of the low frequency storage modulus (measured at $0.01 \mathrm{~Hz}$ ) as a function of the molar percentage of PIEA blocks in the micelle cores for tPEO $\mathrm{P}_{12 \mathrm{k}}(\mathrm{C}=20 \mathrm{~g} / \mathrm{L})$ mixed with IEI triblock copolymer (circles) or IE diblock copolymer (triangle) 

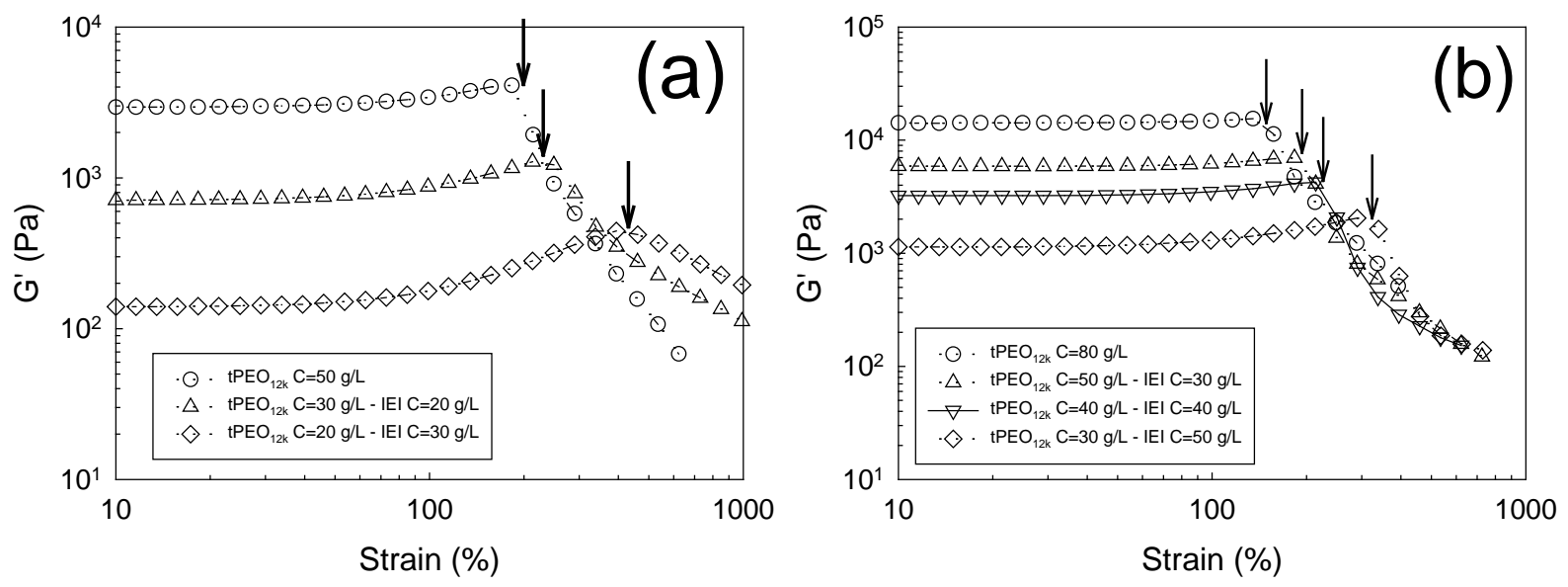

Figure S11. Strain dependence of the elastic modulus ( $\left.\mathrm{G}^{\prime}\right)$ for $\mathrm{tPEO}_{12 \mathrm{k}} / \mathrm{IEI}$ hybrid photo-crosslinked hydrogels at total polymer concentration (a) $\mathrm{C}=50 \mathrm{~g} / \mathrm{L}$ and (b) $\mathrm{C}=80 \mathrm{~g} / \mathrm{L}$ and varying the $\mathrm{tPEO}_{12 \mathrm{k}} / \mathrm{IEI}$ ratio.

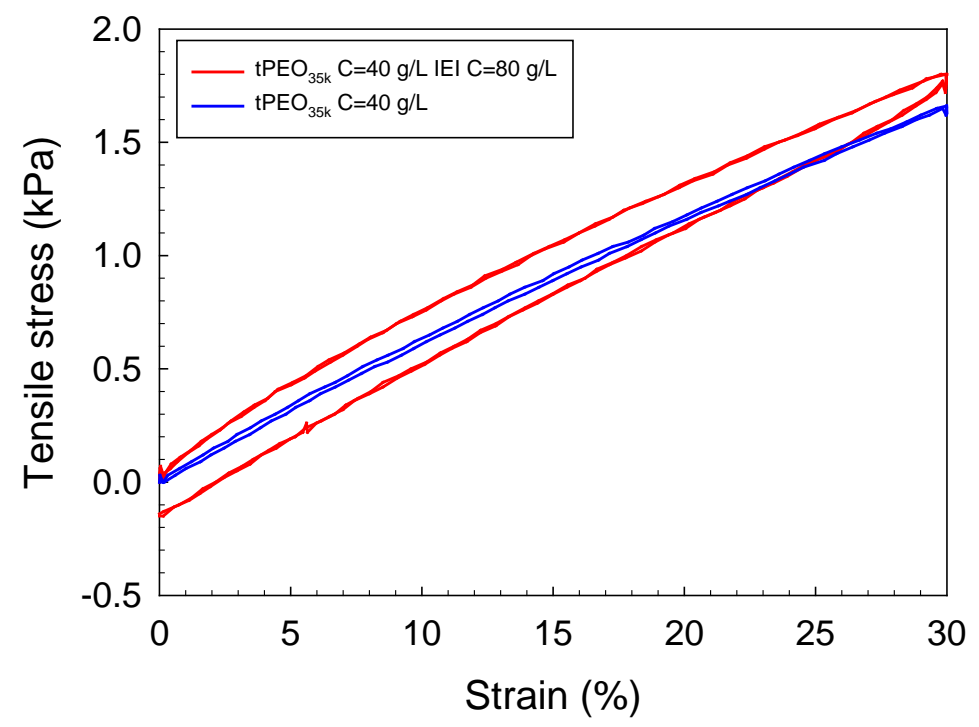

Figure S12. Evolution of the tensile stress with strain during cyclic loading-unloading experiments. 


\section{References}

(1) Kadam, V. S.; Nicol, E.; Gaillard, C. Macromolecules 2012, 45, 410-419.

(2) Klymenko, A.; Nicolai, T.; Benyahia, L.; Chassenieux, C.; Colombani, O.; Nicol, E. Macromolecules 2014, 47, 8386-8393.

(3) Nicol, E.; Derouineau, T.; Puaud, F.; Zaitsev, A. Journal of Polymer Science Part A: Polymer Chemistry 2012, 50, 3885-3894.

(4) Nicol, E.; Nzé, R.-P. Macromolecular Chemistry and Physics 2015, 216, 1405-1414.

(5) Piogé, S.; Fontaine, L.; Soutif, J.-C.; Nicol, E.; Pascual, S. J. Pol. Sci. Part A: Pol. Chem. 2010, 48, 1526-1537.

(6) Kadam, V.; Nicolai, T.; Nicol, E.; Benyahia, L. Macromolecules 2011, 44, 8225-8232.

(7) Annable, T.; Buscall, R.; Ettelaie, R.; Whittlestone, D. J. Rheol. 1993, 37, 695-725.

(8) Lauber, L.; Colombani, O.; Nicolai, T.; Chassenieux, C. Macromolecules 2016, 49, 74697477. 